\title{
ACCIDENTALLY TRUE BELIEF AND WARRANT
}

\begin{abstract}
The Proper Functionist account of warrant - like many other externalist accounts - is vulnerable to certain Gettier-style counterexamples involving accidentally true beliefs. In this paper, I briefly survey the development of the account, noting the way it was altered in response to such counterexamples. I then argue that Alvin Plantinga's latest amendment to the account is flawed insofar as it rules out cases of true beliefs which $d o$ intuitively strike us as knowledge, and that a conjecture recently put forward by Thomas Crisp is also defective. I conclude by presenting my own suggestion as to how the account can be made less vulnerable to counterexamples involving accidentally true beliefs. Although I stay within the confines of Proper Functionism here, I think that my proposal (modulo a few details) could be attached to other externalist accounts of warrant as well.
\end{abstract}

"Warrant" is Alvin Plantinga's term for the "elusive quality or quantity enough of which, together with true belief, is sufficient for knowledge" (Plantinga 1993b, v). According to Plantinga's Proper Functionist account of warrant, a belief $B$ is warranted for a subject $S$ if and only if the following conditions are met:

(1) $B$ is produced by a properly functioning cognitive faculty (or "module" of such a faculty),

(2) The "design plan" governing the relevant faculty or module specifies that it is aimed at acquiring truth,

(3) $B$ is produced in a cognitive environment that is "favourable" for $S$ 's cognitive faculties (i.e., it is "sufficiently similar" to the sort of environment for which $S$ 's cognitive faculties were designed),

(4) The design plan is a good one with respect to that environment (i.e., there is a high objective probability that a belief produced by that faculty in that sort of environment is true). ${ }^{1}$

A number of authors have pointed out that the Proper Functionist account of warrant fails to cope with Gettier-style counterexamples involving what might be called "accidentally true" beliefs. ${ }^{2}$ In this paper, I briefly survey the development of the account, noting the way it was altered in response to such counterexamples (Sections 1-2). I then show that Plantinga's latest amendment to the account is flawed insofar as it rules out cases of true beliefs that $d o$ intuitively strike us as knowledge (Section 3 ), and that a conjecture recently put forward by Thomas Crisp is also 
defective (Sections 4-5). I conclude by presenting my own suggestion as to how the account can be made less vulnerable to counterexamples involving accidentally true beliefs (Section 6). Although I stay within the confines of Proper Functionism in this paper, it should be obvious that my proposal (like Crisp's) can be attached to other externalist theories of warrant as well.

\section{A PROBLEM FOR THE ORIGINAL ACCOUNT}

There are true beliefs that satisfy all of Plantinga's original conditions for warrant (conditions (1)-(4) above) and yet intuitively strike us as merely "accidentally true" and thus as failing to amount to knowledge. Plantinga admits this by way of elaborating a case that was originally put forward by Peter Klein: ${ }^{3}$

Jones owns a Chevrolet van, drives to Notre Dame on a football Saturday, and unthinkingly parks in one of the many spaces reserved for the football coach. Naturally the coach's minions tow Jones' van away and, as befits such lese-majesty, destroy it. By a splendid piece of good luck, however, Jones has won the Varsity Club's Win-a-Chevrolet-Van contest, although he hasn't yet heard the good news. Smith asks Jones what sort of automobile he owns; Jones replies, both honestly and truthfully, 'A Chevrolet van'. Jones' true belief that he owns such a van is true just by accident (more accurately, it is only by accident that Jones happens to form a true belief), however, and hence does not constitute knowledge. (Plantinga 1997, 141)

Let's call this the "Van Case". Now compare the world of the Van Case to a nearby world in which the van is not destroyed and Jones forms the same belief. Both states of affairs involve the same exercise of the same faculties in the same cognitive environment. So according to conditions (1)-(4), either both beliefs have warrant sufficient for knowledge, or both fail to have it. But this result is incorrect: intuitively, if the van is destroyed and the contest is won, then Jones' belief is not knowledge; if the van survives, then Jones' belief is knowledge. Since warrant is supposed to be that quality or quantity enough of which turns true belief into knowledge, the belief in the first case should have warrant sufficient for knowledge, and the belief in the second case should not. Plantinga's conditions (1)-(4) fail to account for this intuitive difference between the two cases; thus, the theory is deficient. Something else is required. 


\section{PLANTINGA'S FIRST AMENDMENT}

In response to such counterexamples, Plantinga (in 1996 and 1997) distinguished between cognitive maxi-environments and cognitive minienvironments. A maxi-environment is the overall situation referred to in condition (3) as a cognitive environment simpliciter. A favourable maxienvironment will include general states that are similar to those on Earth light and air will have their standard properties, the laws of nature will be in effect, other people will behave in a predictable fashion, and so on.

A cognitive mini-environment, on the other hand, is much more narrowly defined. It is the state of affairs that is specific to the particular exercise $E$ of a subject's cognitive powers which produces a belief $B$ (call it a 'MBE' for short). The MBE includes all of the "relevant epistemic circumstances" (so in the Van Case, the MBE includes Jones' van having been destroyed, Jones having won the Varsity Club contest, and so on). ${ }^{4}$ Indeed, a MBE is "maximally specific except for the truth or falsehood of the proposition that $S$ forms a true belief by way of $E$ ". It is "diminished with respect to that proposition" (Plantinga 1996, 313-315). ${ }^{5}$

After defining a MBE in this way, Plantinga provides the following characterization of favourability:

(F-mini) $\quad \mathrm{MBE}$ is favourable for $E$, if and only if, if $S$ were to form a belief by way of $E$ in MBE, $S$ would form a true belief.

Plantinga's suggestion is that (F-mini) can be used, together with

(C-mini) A belief $B$ produced by an exercise $E$ of $S$ 's cognitive powers has warrant sufficient for knowledge only if MBE is favourable for $E$,

to make his account immune to problems posed by accidentally true beliefs like the one in the Van Case. Plantinga's first amendment, then, says that in order for a belief to be warranted it must meet conditions (1)-(4) for warrant and it must satisfy (C-mini) (Plantinga 1996, 326-328).

An objector might protest here that (C-mini) is satisfied in the Van Case. For the MBE in question is clearly such that, if Jones forms the memory belief "I (Jones) own a Chevy van" in that MBE, then Jones acquires a true belief. Thus, by (F-mini), the MBE would appear to be favourable for the relevant exercise of Jones' faculties. According to the first amendment, then, Jones' belief still has warrant sufficient for knowledge. Nothing, it seems, has been accomplished.

Plantinga evades this objection by stipulating that the semantics for (Fmini) is not of the standard (Lewisian, Stalnakerian) variety according to 
which the truth of the antecedent and consequent is sufficient for the truth of the conditional as a whole. In other words, the fact that in the relevant MBE Jones forms the belief "I (Jones) own a Chevy van", together with the fact that that belief is true, is not sufficient for the truth of an instance of the conditional in (F-mini). "What is also required", he writes, "is that there be no sufficiently close possible world in which the counterfactual has a true antecedent and false consequent" (Plantinga 1997, 144n). Plantinga goes on to claim that there are sufficiently close worlds in which Jones believes $B$, but $B$ is false, and thus that Jones' MBE is not favourable according to (F-mini) after all.

Clearly it is right to say that there are such nearby worlds - worlds in which Jones' van is destroyed, say, but Jones does not unwittingly win the van-contest. In such a world, if Jones forms the memory belief "I (Jones) own a Chevy van", then that belief is false. So if that world is sufficiently close to MBE, and the counterfactual semantics of (F-mini) is non-standard in the way that Plantinga stipulates, then by (F-mini) the MBE in question is not favourable for Jones' belief that "I (Jones) own a Chevy van".

But why should we accept the suggestion that such a nearby world is sufficiently close to the world of the original van case? Why not think that the only sufficiently close worlds are the many nearby worlds in which the relevant Gettier-features do obtain? Plantinga doesn't say. My sense is that the procedure for determining which of the worlds are sufficiently close when applying a principle like (F-mini) with non- standard semantics is likely to be (at best) vague and context-sensitive. Since there is no principled reason for thinking that in this context a Gettier-free world is sufficiently close to the Gettier-plagued MBE of the Van Case, the assumption that it is sufficiently close seems arbitrary.

\section{PLANTINGA'S SECOND AMENDMENT}

In his most recent work on this problem, Plantinga abandons the counterfactual analysis of favourability in favor of one that focuses on the conditions within a Gettier-plagued mini-environment. Plantinga asks us to consider one of the states of affairs included in a MBE - the state of affairs that is detectable by $E$ at $t$. He calls this state of affairs "DMBE". (F-mini) is then replaced by 
(F-mini*) MBE is favourable just if there is no state of affairs $\mathrm{A}$ included in MBE but not in DMBE such that the objective probability of $B$ with respect to the conjunction of DMBE and A falls below $r$, where $r$ is some real number representing a reasonably high probability. (Plantinga 2000, 160).

There are problems with this second amendment as well. Consider the following case:

Johnson, a man who has recently taken up bird-watching, goes out one day to look for birds to add to his life list. He has acquired his ornithological training by reading some birding books and by listening to recordings of birdcalls. Johnson hasn't seen a song sparrow (Melospiza melodia) before, but he is familiar with their plumage, body shape, and calls. Unbeknownst to him, however, song sparrows have suffered from a devastating virus in recent weeks, and there are now only two of them left on the entire continent. The Lincoln's sparrow (Melospiza lincolnii), which looks and sounds very similar to the song sparrow, has been unaffected by the virus and there are still quite a few of them living in Johnson's region.

As Johnson strolls through the forest, he hears what seems to him to be the call of a song sparrow. He approaches the relevant tree to get an up-close look at the bird. The bird is, in fact, one of the two remaining song sparrows on the continent. Johnson studies the bird for some time: it looks to him like the song sparrow pictured in his books, and its call sounds like the recordings he has heard. On this basis these observations, Johnson assents, with a degree of strength that is just enough to put him over the threshold required for knowledge, to the proposition that the bird he is observing is a song sparrow. He then adds it to his life list and goes happily on his way.

Let's assume that conditions (1)-(4) are met in this case: Johnson's cognitive faculties are functioning properly and aimed at truth in a favorable maxi-environment, and they were produced in accordance with a good design plan. What about the mini-environment? Is it favourable?

According to the second amendment, the MBE here is not favourable. For the complex state of affairs, call it $A$, of the song sparrow's being nearextinct and the Lincoln sparrow's looking and sounding very similar to the song sparrow, is included in the MBE, though not in the DMBE. Moreover, 
the objective probability of Johnson's $B$ (the belief that "That bird is a song sparrow"), on the conjunction of DMBE and $A$, is quite low. ${ }^{6}$ So, by (F-mini*), $B$ does not enjoy warrant sufficient for knowledge. And yet I think that our intuition about the case is that $B$ does count as knowledge for Johnson. After all, it wasn't just dumb luck: Johnson walked up to the bird, studied it closely, used his background knowledge, was aware of no evidence against $B$, and so forth. ${ }^{7}$

Counterexamples like this can be multiplied as needed. What they show is that the second amendment is flawed insofar as it fails to isolate and rule out only the sorts of beliefs that are typical of Gettier examples. The first amendment ruled out too little, the second amendment rules out too much. Such is often the case with responses to Gettier problems: it is very hard to find a principle that gets it just right.

\section{CRISP'S CONJECTURE}

In a recent article, Thomas M. Crisp offers a still different account of how to revise the environmental condition so as to make the Proper Functionist account "less vulnerable" to counterexamples involving accidentally true beliefs (Crisp 2000, 49). Crisp doesn't note that his condition (changing a few details) could be annexed to almost any externalist account of warrant in an attempt to make it less vulnerable to such counterexamples. This potential for wide-ranging applicability makes Crisp's conjecture worthy of serious consideration. Here, however, I will first provide a reason to think the account needs revision, and then present a case of accidentally true belief which even the revised account fails to handle.

In order to assess Crisp's proposal, we need to have four concepts in hand. Taking $p, q$, and $r$ to be propositions, let it be the case that:

(1) " $P(p / q)$ " is short for "the epistemic probability of $p$ given $q " .8$

(2) $\quad q$ confirms $p$ for $S$ iff $P(p / q \& k)>P(p / k)$, where $k$ is the conjunction of $S$ 's background beliefs.

(3) $\quad p$ defeats a belief $B$ for $S$ iff $P(B / p \& k)<P(B / k)$, and $P(B / p \& k)<n$, where $n$ is some real number representing the point at which a properly functioning human would cease to believe that $B .{ }^{9}$

(4) $\quad p$ is an undefeated defeator of $B$ for $S$ iff $p$ defeats $B$ for $S$ and there is no true proposition $r$ such that (i) $r$ defeats neither $B$ nor $n o t-B$ for $S$, and (ii) $P(B / p \& r \& k)>n .{ }^{10}$ 
Using these concepts, Crisp defines unfavourability in a MBE as follows:

(U) $\quad M B E$ is an unfavourable mini-environment for exercise $E$ of $S$ 's cognitive faculties resulting in the belief that $B==_{\mathrm{df}}$ there are propositions $p$ and $q$, neither of which are believed by $S$, such that

(a) MBE entails not- $p$ and $q$, and

(b) $P(p / k)>P(q / k)$, and

(c) both $p$ and $q$ confirm $B$ for $S$, and

(d) not- $p$ is an undefeated defeator of $B$ for $S$ and not- $q$ does not defeat $B$ for $S$.

A favourable mini-environment is then defined as one that is not unfavourable according to (U) (Crisp 2000, 48-49).

Now clearly, each of (U)'s conditions are satisfied in the Van Case, where $B=$ "I (Jones) own a Chevy van", $p=$ "It's not the case that my van has been destroyed", and $q=$ "I just won the Chevy van contest". Thus, Jones' belief $B$ is formed in a MBE that is unfavourable according to (U). Since the MBE in the Van Case is unfavourable according to (U), (C-mini) will now give us the correct result that Jones' belief does not have warrant sufficient for knowledge. ${ }^{11}$

\section{AN OBJECTION TO CRISP, AND A COUNTEREXAMPLE}

Note that according to Crisp's definition of an "undefeated defeator", not$p$ is an undefeated defeator of $B$ for $S$ only if there is no true proposition $r$ such that

(i) $\quad r$ defeats neither $B$ nor not- $B$ for $S$, and

(ii) $\quad P(B / n o t-p \& r \& k)>n$.

Is there such a true proposition in the Van Case? The proposition labeled " $q$ " above ("I just won the Chevy van contest") seems to be a likely candidate. It is certainly true. And it satisfies (ii) insofar as $B$ is clearly believable ${ }^{12}$ for Jones on the basis of not- $p \& q \& k .^{13}$

However, $q$ fails to satisfy (i), since it defeats not- $B .{ }^{14}$ Assuming that there is no other proposition that could satisfy both (i) and (ii) in this case, not- $p$ will count as an undefeated defeator of $B$ on Crisp's definitions even in the face of $q$. Thus condition (d) of (U) is met. 
Although this is the result that Crisp wants, something has clearly gone wrong. A proposition like not- $p$ should not be considered an undefeated defeator of $B$ when there is a true proposition like $q$ in the neighborhood. For the truth of $q$ clearly takes away not- $p$ 's capacity to defeat $B$ for Jones. In other words, it's clear that although $B$ ("I own a Chevy Van") is defeated for Jones by not- $p$ ("My van has been destroyed"), $B$ becomes eminently believable again when Jones learns that $q$ ("I just won the Chevy van contest"). And, as we just saw, it is this fact that allows $q$ to satisfy (ii).

Crisp makes the satisfaction of (i) and (ii) jointly necessary for a true proposition like $q$ to prevent not- $p$ from being an undefeated defeator of $B$. And, again, satisfying (i) is not possible for $q$, since it defeats not- $B$. But note: it is precisely the same feature of $q$ that both provides Jones with a positive reason to believe $B$ and serves to defeat not- $B$ for him. In other words, it is the same feature of $q$ that makes it both able to satisfy (ii) and unable to satisfy (i). This would be true for any other proposition that gave Jones a positive reason to believe $B$.

Let's say that a proposition is a rebutting defeator of a defeator of a belief $B$ only if it provides a positive reason for subject $S$ to believe $B$, despite the truth of the original defeator. My objection to Crisp, in short, is that his definition of an undefeated defeator simply rules out a priori the possibility that there are rebutting defeators of defeators. For, as was just noted, a proposition like $q$ will be unable to satisfy condition (i) just insofar as it provides a positive reason to believe $B$ and thereby defeats $n o t-B$. This restriction, seen in the light of day, is obviously wrong-headed. $q$ seems to be a perfectly good example of a rebutting defeator of not- $p$, and further examples of rebutting defeator-defeat could be brought forward as necessary. We do not want an account that fails to allow for rebutting defeator-defeat.

Crisp's best response to this objection, I think, is to say that his original definition was not meant to characterize defeator-defeat broadly speaking, but rather defeator-defeat of the "undercutting" variety only. Let's say that a proposition is an undercutting defeator of a defeator of a belief $B$ only if it provides a reason for $S$ to doubt or deny that the original defeator would not be true unless $B$ were false. ${ }^{15}$ Crisp could respond to my objection by claiming that a MBE is unfavorable if there is no undercutting defeator for the relevant not- $p$, regardless of whether there is a rebutting defeator. $\mathrm{He}$ could then revise condition (d) in (U) to reflect this change. The revised condition would read

$\left(\mathrm{d}^{*}\right) \quad$ not- $p$ is a non-undercut defeator of $B$ for $S$ and not- $q$ does not defeat B for $S$ 
where a "non-undercut defeator" would be defined exactly as Crisp originally defined an "undefeated defeator" - viz.,

not- $p$ is a non-undercut defeator of $B$ for $S$ iff not- $p$ defeats $B$ for $S$ and there is no true proposition $r$ such that (i) $r$ defeats neither $B$ nor not- $B$ for $S$, and (ii) $P(B /$ not- $p \& r \& k)>n$.

Unfortunately, there are mini-environments which are both clearly unfavourable and yet not captured even by a revised version of (U) which includes $\left(\mathrm{d}^{*}\right)$ instead of $(\mathrm{d})$. Consider the following Watermill Case:

Susan looks at her watch and sees that it is three o'clock. She then glances at the clock on the wall, sees that it reads three o'clock, and forms the belief that the clock on the wall is a reliable indicator of the time. Unbeknownst to Susan, four other facts obtain: the clock is unplugged; the clock is capable of running on batteries; there are no batteries in the clock at the present time; and the clock's second hand is calibrated, via gears and other mechanisms, to a nearby watermill which just happens to have been spinning around at exactly one revolution per minute for the last three months, and will continue to do so for at least three more months.

Now clearly this MBE does not satisfy (d*) in our revised (U), where $B=$ "The clock is a reliable indicator of the time", $p=$ "The clock is plugged in", $q=$ "The second-hand is calibrated to a nearby watermill which just happens to be rotating at one revolution per minute" and $r=$ "The clock is capable of running on batteries".

$\left(d^{*}\right)$ is not satisfied because not- $p$ fails as a non-undercut defeator of $B$ for Susan. That, in turn, is because there is a true proposition $r$ such that (i) $r$ defeats neither $B$ nor $n o t-B$ for Susan and (ii) $P(B /$ not- $p \& r \& k)>n \cdot{ }^{16}$ I can see no other way of setting things up such that this MBE satisfies the revised (U).

Thus, even on the revised version of Crisp's account, it looks like Susan's belief that $B$ in the Watermill Case will have warrant sufficient for knowledge. ${ }^{17}$ But our clear intuition, presumably, is that Susan's $B$ does not have warrant sufficient for knowledge. For $B$ is only accidentally true (after all, it is a mere accident that the water in the brook is not flowing slightly faster or slower!). ${ }^{18}$ Insofar as Crisp's conjecture fails to deliver the proper intuitive result for this logically possible case, it is flawed and thus unable to save analyses of warrant (Proper Functionist or otherwise) from Gettier-style difficulties involving accidentally true beliefs. 


\section{AN ALTERNATE PROPOSAL}

The root problem with Plantinga's two amendments to the Proper Functionist account is that mini-environments as he conceives of them are too specific. Recall that a MBE is defined as the state of affairs that is specific to one exercise of a subject's cognitive faculties and to the one belief that is produced by that exercise. That means that no two beliefs will have the same MBE.

By defining a MBE as belief-specific in this way, Plantinga makes it impossible for an analysis of MBE-favourability to appeal to other beliefs that could have been formed in the same mini-environment. Thus, Plantinga's first (F-mini) appeals to nearby worlds in which the same belief is formed in somewhat different circumstances. In Section 2, I suggested that this is an unhelpful move insofar as the appeal to counterfactual circumstances is of dubious relevance when trying to determine the favourability of the actual circumstances. I now want to suggest that problems involving accidentally true beliefs like that of the Van Case can only be solved by appealing to different beliefs that might have been formed in the same circumstances.

Suppose we define a mini-environment as the maximally specific state of affairs at $t 0$, where $t 0$ is the vanishing instant just before the time, $t$, at which the subject, $S$, forms a belief, $B$. Suppose further that the favourability of such a mini-environment is made relative not just to one belief that $S$ might form at $t$ (that's too narrow), and not to all of the beliefs that might be produced by one of $S$ 's faculties at $t$ (that's too wide), but rather to all of the beliefs that might be produced by one of $S$ 's faculties about one intentional object at $t$. Here is the principle (I'll use 'ME' rather than 'MBE' to denote a mini-environment, since mini-environments are no longer belief-specific):

(F-mini**) A mini-environment, $\mathrm{ME}$, is favourable for an exercise, $E$, of one of $S$ 's cognitive faculties, $F$, with respect to a particular object in that environment, $O$, just in case any belief $B$ about $O$ that $S$ might form by way of exercising $F$ in ME is such that, if $B$ meets the other conditions for warrant, then $B$ is objectively likely to be true. ${ }^{19}$

Less technically, a ME is favourable for the exercise of $S$ 's visual senseperception faculty, say, with respect to an object in her visual field just in case any vision-perceptual belief that she might form about that object, provided it meets the other conditions for warrant, is objectively likely to be true. 
(F-mini**) succeeds in ruling out accidentally true beliefs like that of Jones the van-owner and Susan the clock-watcher without ruling out perfectly good beliefs like that of Johnson the bird-watcher. Jones' new van is the relevant $O$ in the Van Case, and any memory-belief that Jones might form about $O$, provided it meets the other conditions for warrant, will have a low objective probability of being true. The set of such beliefs would include "I (Jones) bought the van eight years ago", "My van has over 50,000 miles on it", "My wife has ridden in the van many times", and so forth. Most of these beliefs are false. So by (F-mini**), the one or two true beliefs in this set (including the belief that "I (Jones) own a Chevy van") are produced in a mini-environment that is not favourable. By (C-mini), these beliefs lack warrant sufficient for knowledge. ${ }^{20}$

Susan's belief that the clock on the wall is reliable in the Watermill Case is likewise ruled out by (F-mini**), provided we specify that the object of her belief here is not really the clock as a whole but rather the time-keeping mechanism of the clock. ${ }^{21}$ The belief is ruled out because any other (otherwise warranted) inference about the clock's time-keeping mechanism that she might make on the basis of her perceptual beliefs is objectively likely to be false. The set of such beliefs includes "The clock's mechanism is functioning normally", "The clock will probably keep time until its batteries run out or it is unplugged", "The clock's time-keeping mechanism is being powered electrically" and so on. The ME for beliefs Susan might form by making inferences from perceptual beliefs about the clock's time-keeping mechanism is thus unfavourable according to (Fmini**). And so the few true inferences from her perceptual beliefs that Susan might form about the clock's time-keeping mechanism - including the inference that "The clock is a reliable indicator of the time" - will, by (C-mini), fail to have warrant sufficient for knowledge.

Johnson's belief about the song sparrow, on the other hand, is formed in a mini-environment that passes (F-mini**) with flying colours. For consider the set of beliefs that Johnson might form about the bird with his perceptual faculties: it includes beliefs like "The sparrow is seated on a branch", "The bird is softly warbling", "That's a distinctive plumage", and so on. Most of the beliefs in this set would be true, and thus by (F-mini**) and (C-mini), Johnson's true belief that "That bird is a song sparrow" will have warrant sufficient for knowledge.

\section{CONCLUSION}

We have seen that the Proper Functionist account of warrant as it originally stood failed to rule out certain Gettier-style cases of accidentally true 
belief. The first amendment was meant to meet these counterexamples, but it did so by appealing to other possible worlds that aren't clearly relevant to the Gettier-stricken worlds themselves. The second amendment incorrectly denied warrant to clear cases of knowledge like that of Johnson the bird-watcher. Crisp's conjecture, on the other hand, is susceptible (even when provided with necessary revisions) to counterexamples such as the Watermill Case.

The amendment I have proposed here provides a different way of construing favourability in a mini-environment, a way that (I submit) does make the Proper Functionist account less vulnerable to Gettier-style counterexamples involving accidentally true beliefs. Let me note again, however, that other conditions (conditions (1)-(4) above in the Proper Functionist account, for example) will be required in order to handle other sorts of Gettier problems. ${ }^{22}$ My proposal, in sum, says that if the circumstances surrounding $S$ 's faculty-specific beliefs about a particular object make it such that any otherwise warranted belief she might form with that faculty about that object at that time is likely to be false, then all bets are off regarding her beliefs about that object produced by that faculty at that time.

\section{ACKNOWLEDGEMENTS}

Thanks to J. Todd Buras, Thomas Crisp, Keith DeRose, Andrew Dole, Desmond Hogan, Alvin Plantinga, Nicholas Wolterstorff, and an anonymous Synthese referee for helpful comments on earlier drafts.

\section{NOTES}

1 For Plantinga's own (slightly variant) articulations of the "central core" of the Proper Functionist account see Plantinga (1993b, 19, 194) and (2000, 156).

2 See Feldman (1996), Klein (1996), Greene and Balmert (1997), and Crisp (2000). Plantinga's amendments are in Plantinga (1996, 1997, 2000).

3 I have changed Plantinga's first-person description of the case to a third-person description. For the inspiration behind the case, see Klein (1996).

4 A state of affairs $X$ is "included" in another state of affairs $Y$ iff necessarily, if $Y$ obtains, then $X$ obtains.

5 For more on what it is to "diminish" a world with respect to a proposition, and for some potential problems with Plantinga's way of doing it, see Crisp (2000, 44n). I will not be concerned with this issue here, and so I will assume (as Crisp ultimately does) that some other way of capturing the intuitive idea of a state of affair's being "diminished" with respect to a proposition can be found. 
6 We have to be careful to specify here that the fact that the bird is a song sparrow is not itself detectable by $E$ (i.e., by the relevant exercise of Johnson's perceptual faculties). Otherwise, that fact would be included in the DMBE and thus ruin the counterexample. Fortunately, given Johnson's status as a novice bird-watcher who had never seen a live song sparrow before, I think that it is quite plausible to say that only lesser facts - facts such as that the bird looks like a song sparrow and that it has a call like that of a song sparrow - are actually detectable by $E$. Given this, and given that Johnson is a properly functioning subject who is aware of no evidence against $B$, he naturally forms $B$ upon detecting such facts. This belief counts as knowledge, I submit, but, all the same, Johnson couldn't detect the fact that the bird is a song sparrow by $E$.

7 These facts distinguish the present case from the (otherwise analogous) Phony Barn Case. In the latter, the subject is simply driving by and forms the casual belief that "That's a fine barn", whereas Johnson goes and gets an up-close look at the bird, studies it for some time, walks around it etc. This difference explains the fact that the subject's belief in the Phony Barn Case doesn't count as knowledge, whereas Johnson's belief, I think, clearly does.

8 Crisp leaves his notion of epistemic probability undefined. I will follow him in this.

9 Crisp (plausibly) claims that the value of $n$ will vary from context to context.

${ }^{10}$ I have used " $r$ " here where Crisp uses " $q$ " in order to preserve clarity later in the paper. Nothing substantive hangs on this change.

${ }^{11}$ Crisp's account also succeeds in neutralizing other notoriously problematic Gettier-style cases, including Russell's Stopped Clock Case and the family of Grabit Cases. For more on these and related cases, see Shope (1983).

12 Here and in what follows I will use "believable" to mean "has an epistemic probability greater than $n$ " and "unbelievable" to mean "has an epistemic probability equal to or less than $n$ ".

13 That is: it is believable for Jones that "I own a Chevy van" if he knows that his old van has been destroyed and that he has just won the Chevy van contest.

${ }^{14} q$ defeats not- $B$ because $P($ not- $B / q \& k)<P($ not-B/k) and, moreover, $P($ not$B / q \& k)<n$. In other words: if Jones believes that he just won the Chevy van contest, then the epistemic probability for him that he doesn't own a Chevy an will be more lower than $n$.

15 I have been influenced here by Pollock and Cruz's definition of an undercutting defeator (cf. Pollock and Cruz 1999, 196).

16 The epistemic probability of $B$ given not- $p \& r \& k$ is greater than $n$, I submit, because of the crucial fact that Susan glances at her watch and notes that it too reads three o'clock. If this component of the case were left out, a properly functioning subject might, upon learning that the clock is unplugged but also capable of running on batteries, simply be agnostic about whether the clock is a reliable indicator of the time. I am grateful to a Synthese referee for pointing this out.

${ }^{17}$ Susan's belief also meets conditions (1)-(4) for warrant in the Proper Functionist account to which Crisp is proposing an amendment. So it counts as a counterexample to the account as a whole.

18 Cases that function in the same way as the Watermill Case can be multiplied as needed. The essential ingredient is a connection between the clock and some non-intentional process which makes $B$ true, but only "by accident".

19 This is clearly in the spirit of Plantinga's original condition (4), which says that there must be a high objective probability that any belief produced by a certain faculty in a given 
maxi-environment will be true. Note, too, that the set of beliefs appealed to here includes all of the otherwise warranted beliefs that the subject might form about $O$ with $F$ in ME. This rules out potential counterexamples in which $S$, for whatever reason, simply happens to form mostly false (but warranted) beliefs about $O$ with $F$, and in which the one or two true (and warranted) beliefs produced by $F$ about $O$ still strike us intuitively as knowledge (and thus should not be deemed unsatisfactory by a principle like (F-mini**)). Finally, I am setting aside, for the purposes of this paper, the "generality problem" regarding how to specify the faculty involved in belief-production.

20 This proposal also succeeds in ruling out other cases that evade Plantinga's first amendment, such as the case of the twins Peter and Paul and Russell's Stopped Clock Case (cf. Plantinga 1997, 142-143).

21 The relevant $\mathrm{O}$ can't just be the clock überhaupt, since Susan could infer any number of otherwise warranted true beliefs about it from her perceptual beliefs (i.e., she could infer beliefs such as "the clock was made in Switzerland", "the clock is quite old", and so on). Thus $\mathrm{O}$ has to be specified as the time-keeping mechanism of the clock. In employing (F-mini**) it will often be crucial to specify the $O$ in question very carefully.

22 Plantinga shows how conditions (1)-(4) can handle the original cases in Gettier (1963) as well as various other sorts of cases in Plantinga (1993b), especially chapter 2.

\section{REFERENCES}

Crisp, T.: 2000, 'Gettier and Plantinga's Revised Account of Warrant', Analysis 60, 42-50. Feldman, R.: 1996, 'Plantinga, Gettier and Warrant', in J. Kvanvig (ed.), Warrant in Current Epistemology: Essays in Honor of Plantinga's Theory of Knowledge, Roman and Littlefield, New York, pp. 199-220.

Gettier, E.: 1963, 'Is Justified True Belief Knowledge?', Analysis 23, 121-123.

Greene, R and Balmert, : 1997, 'Two Notions of Warrant and Plantinga's Solution to the Gettier Problem', Analysis 57, 132-139.

Klein, P.: 1996, 'Proper Function, Reliabilism, and Defeasibility', in J. Kvanvig (ed.), Warrant in Current Epistemology: Essays in Honor of Plantinga's Theory of Knowledge, Roman and Littlefield, New York, pp. 97-130.

Plantinga, A.: 1993a, Warrant: The Current Debate, Oxford University Press, New York. Plantinga, A.: 1993b, Warrant and Proper Function, Oxford University Press, New York. Plantinga, A.: 1996, 'Respondeo', in J. Kvanvig (ed.), Warrant and Current Epistemology: Essays in Honor of Plantinga's Theory of Knowledge, Rowman and Littlefield, Lanham, MD, pp. 307-378.

Plantinga, A.: 1997, 'Warrant and Accidentally True Belief', Analysis 57, 140-145.

Plantinga, A.: 2000, Warranted Christian Belief, Oxford University Press, New York.

Pollock, J. and J. Cruz: 1999, Contemporary Theories of Knowledge, Revised edn, Rowman and Littlefield, Lanham, MD.

Shope, R.: 1983, The Analysis of Knowing, Princeton University Press, Princeton.

Cornell University

218 Goldwin Smith Hall

Ithaca, NY 14853

U.S.A. 